\title{
Doxycycline Pleurodesis in Hepatic Hydrothorax
}

\author{
El-Said M.G. EL-Badrawy, MD, and Nasr E. Mohammed, MD \\ Tropical Medicine and Cardiothoracic Surgery Departments \\ Faculty of Medicine \\ Zagazig University \\ Zagazig, Egypt
}

\begin{abstract}
Background/Aim: Hepatic hydrothorax (HHyd) is usually recurrent and remains a difficult clinical problem. Transjagular Intrahepatic Portosystemic Shunt (TIPSS) is commonly used in the treatment of HHyd. While it is highly effective, it is more expensive and more difficult to perform and needs more experience, especially in mixed postviral and bilharzial cirrhosis, which is common in Egypt. The aim of this study is to evaluate the effectiveness of the simpler, easier, cheaper and less invasive procedure of doxycycline pleurodesis in critically ill patients with recurrent symptomatic HHyd not responding to conservative treatment and thoracocentesis.

Patients and Methods: This study was done on 20 adult cirrhotic patients. According to Child classification, 10 patients were Class $B$ and 10 were Class $C$. Eighteen patients had right hydrothorax and 2 patients had left hydrothorax. All patients underwent a full medical history and thorough clinical examination with strict follow up, abdominal sonar, liver function tests before and after pleurodesis, repeated chest X-rays before and after pleurodesis at 3 days, 1 week, 1 month and 6 months, paracentesis, pleurocentesis with analysis of aspirate, CBC and electrocytes. All patients received $500 \mathrm{mg}$ of doxycycline in $50 \mathrm{cc}$ of normal saline via thoracostomy.

Results: The success rate was ( $85 \%, 17$ out of 20 cases) comparable to TIPSS (100\%) after the first instillation with no recurrence up to a median of 9 months follow up. The success rate of reinstillation, in three cases of continued high volume tube output, was $66.6 \%$. The overall success rate was 95\%. Mean duration of hospitalization for the first instillation was 5 days, and 10 days for the second instillation. There was no significance difference in liver function tests, electrolytes and abdominal sonar findings before and after pleurodesis. Fever and pleural pain were the most common adverse effects but were mild in degree and short in duration.

Conclusion: Doxycycline pleurodesis is an easy, safe, inexpensive, and highly effective (85\%) treatment comparable to TIPSS in critically ill patients with recurrent HHyd not responding to treatment. It is a good alternative to TIPPS in poor developing countries.
\end{abstract}

Key words: Hepatic hydrothorax, Cirrhosis, Pleurodesis, Doxycycline, Transjugular Intrahepatic Portosystemic Shunt

Introduction

Hepatic hydrothorax (HHyd) as originally Hdescribed by Leiberman et al. is the efflux of ascitic fluid into the pleural space, usually through a diaphragmatic defect and/or diaphragmatic lymphatics along a peritoneal-pleural pressure gradi- ent. ${ }^{1}$ HHyd occurs bilaterally but more commonly on the right side.2 Sometimes HHyd occurs without ascites, which may be due to decreased intravascular oncotic pressure from diminished protein biosynthesis by the cirrhotic liver. ${ }^{3}$

Treatment of HHyd should be directed towards 
control of ascites and supportive management of the liver. However, HHyd is usually recurrent and remains a difficult, persistent clinical problem. In these situations, chemical pleurodesis can be considered. ${ }^{4}$ Despite the promising results, there is a high mortality rate in patients with cirrhosis who undergo Transjagular Intrahepatic Portosystemic Shunt (TIPSS), particularly in the HHyd group. This is because the patients with HHyd tend to have more advanced disease. There are also several complications of TIPPS like encephalopathy (50\%), coagulopathy, early and/or late stent stenosis or thrombosis. ${ }^{5}$ Also, TIPSS may be a difficult procedure to perform in our patients who actually suffer from mixed postviral and bilharzial cirrhosis. Because of this, alternative treatments have been explored. Doxycycline pleurodesis was effective in spontaneous pneumothorax. It was also equally effective in experiments in rabbits with HHyd and in malignant pleural effusions. ${ }^{6,7}$ The aim of this prospective study was to evaluate the effectiveness of doxycycline pleurodesis in recurrent symptomatic HHyd not responding to conservative treatment in critically ill patients in developing countries.

\section{Patients and Methods}

This study was conducted on 20 patients between May 2003 and May 2004. All patients had a cirrhotic liver. According to Child classification, 10 patients were Class B and 10 were Class C. Sixteen patients had right hydrothorax and ascites, two had right hydrothorax without ascites with no underlying pulmonary, cardiac or renal diseases, and two patients had left hepatic hydrothorax.

All these patients did not respond to medical treatment and repeated thoracocenteses and remained symptomatic.

All patients underwent the following investigations:

1. Full medical history and thorough clinical examination with strict follow up.

2. Abdominal sonar before and after pleurodesis.

3. Liver function tests before and after pleurodesis.

4. Repeated chest X-ray examination before and after pleurodesis 3 days, 1 week, 1 month and 6 months.

5. Paracentesis and pleurocentesis and analysis of aspirate.

6. $\mathrm{CBC}$ and electrocytes.

\section{Technique}

Chest tubes were inserted through the $6^{\text {th }}$ intercostal space in the midaxillary line. Patients received intravenous infusions of salt free human albumin (SFHA) and/or Hydroxyethyl strach 6\% (HAES) solution to guard against hypovolemia and renal complications and to prevent fluid reaccumulation. Doxycycline pleurodesis was done when the amount of fluid drained became less than $100 \mathrm{ml} / 24$ hours, usually after 2-8 days.

Pleurodesis was done by injecting $500 \mathrm{mg}$ doxycycline in $50 \mathrm{ml}$ of isotonic sodium chloride through the chest tube under sterile conditions, followed by an additional injection of $25-50 \mathrm{ml}$ of normal saline through the chest tube into the pleural cavity. ${ }^{6}$ The chest tube was clamped for two hours. The patients underwent rotational maneuvers (15 minutes each in the right lateral, left lateral, supine, and prone positions) during the time that the chest tube was clamped. The tube was then reattached to the underwater seal. When chest tube drainage became less than $100 \mathrm{ml} / 24 \mathrm{~h}$, it was removed. Another $500 \mathrm{mg}$ doxycycline instillation was done within one week of initial pleurodesis in cases with continued high output of chest tube drainage $>100 \mathrm{ml} /$ day, and this was not considered as treatment failure. If the reaccumulation occurred after one week (in 3 cases), this was considered a failure, and doxycycline pleurodesis was repeated after 10 days. If reaccummulation occurred after seven days of the second installation, it was considered a failure. Successful pleurodesis was defined as the absence of any pleural fluid reaccumulation in all follow up radiographs.

\section{Results}

The observation period ranged between 6-12 months, with a median of 9 months. There were three recurrences in which reinstallation of another $500 \mathrm{mg}$ doxycyline after 10 days of the initial pleurodesis was administered.

The amount of pleural fluid aspirated at the initial procedure ranged between 3 and 6 liters with a mean of 4 . In the reinstallation group, the volume ranged between 1 and 3 liters with a mean of 2 liters. The volume of SFHA infused in the initial procedure ranged between 50 and $300 \mathrm{mls}$, mean $150 \mathrm{mls}$ and in the reinstallation group, the range was 50 to $150 \mathrm{mls}$, with a mean of $100 \mathrm{mls}$. The volume of HEAS infused in the initial procedure ranged between 500 and 1500 $\mathrm{mls}$, the mean $1000 \mathrm{mls}$ and in the reinstallation 
Table 1. Liver function tests and electrolytes, before and after doxycycline pleurodesis.

\begin{tabular}{|c|c|c|c|c|}
\hline & Normal value & Before pleurodesis (20) & After pleurodesis (20) & Sig* \\
\hline Bilirubin: & $0.2-1 \mathrm{mg} / \mathrm{dl}$ & $1.54 \pm 0.40$ & $1.60 \pm 0.45$ & NS \\
\hline Direct & $0.0-0.2 \mathrm{mg} / \mathrm{dl}$ & $0.4 \pm 0.2$ & $0.45 \pm 0.21$ & NS \\
\hline Albumin & $3.6-5.1 \mathrm{gm} / \mathrm{dl}$ & $2.4 \pm 0.5$ & $2.35 \pm 0.45$ & NS \\
\hline ALT & $41 \mathrm{u} / 1$ & $50 \pm 15$ & $51 \pm 13$ & NS \\
\hline AST & $41 \mathrm{u} / 1$ & $55 \pm 14$ & $56 \pm 14$ & NS \\
\hline Alkaline phosphatase & 3-13 KAU & $12 \pm 3$ & $12 \pm 4$ & NS \\
\hline $\mathrm{K}+$ & $3.5-5 \mathrm{mmol} / \mathrm{L}$ & $3.5 \pm 0.5$ & $2.7 \pm 0.6$ & NS \\
\hline $\mathrm{Na}+$ & $135-148 \mathrm{mmol} / \mathrm{L}$ & $133.3 \pm 8.6$ & $132.2 \pm 7.8$ & NS \\
\hline
\end{tabular}

*Two-tailed student t-test

group, the volume infused ranged between 500 and $1000 \mathrm{mls}$, with a mean of $750 \mathrm{mls}$. The liver function tests and serum electrolyte levels were not significantly different after the pleurodesis from the pretreatment levels (Table 1).

\section{Discussion}

Many studies showed that doxycycline pleurodesis is an effective and safe means for achieving apposition of the pleural surfaces 2,6

Recurrence of pleural effusion in hepatic ascites is common and causes respiratory distress. Cirrhotic patients cannot stand a large dose of diuretics. It is very expensive to use continuous intravenous infusion of salt free human albumin. Doxycycline was found to be an effective and safe method to prevent recurrence of pleural effusion. In comparison with TIPSS, which is more commonly used in developed countries, it was only slightly less effective (85\% versus $100 \%$ ). TIPPS is associated with significant complications, especially in critically ill patients. These include encephalopathy (50\%), early and late stent stenosis, and in some cases, death. ${ }^{5}$ TIPSS is also much more expensive and more invasive than doxycycline pleurodesis. Also some patients had HHyd with no ascites which results from decreased oncotic pressure due to hypoalbuminaemia rather than from the portal hypertension, so they are not candidates for TIPSS. Most Egyptian patients cannot financially afford the TIPPS procedure. Moreover, the TIPPS procedure is more technically difficult in Egyptian patients because their cirrhosis is chiefly of mixed etiology, postviral and bilharzial. Bilharzia causes very tough periportal fibrosis, which makes creation of stent intrahepatically very difficult.

Intrapleural installation of chemicals destroys the parietal and visceral mesothelium and causes the formation of adhesions, as shown by in vitro investigations. ${ }^{6,7}$ In the present study doxycyline was used instead of tetracycline to avoid its hepatorenal toxicity. ${ }^{8}$

The optimal dose of doxycycline required for effective pleurodesis was $500 \mathrm{mg}{ }^{7}$. Reinstallation of another $500 \mathrm{mg}$ doxycycline was effective in 2 of the 3 patients who had recurrence of hydrothorax. The amount of exudate from the drain was markedly less than that noted by Uhle et al., 1983 who used silver nitrate pleurodesis versus tetracycline pleurodesis in spontaneous pneumothorax. ${ }^{6}$ Also Ahmed et al., 1996 noted the same observation by using talc powder pleurodesis in HHyd.9 The duration of drainage after doxycycline pleurodesis was less than in talc powder pleurodesis ${ }^{9}$ and silver nitrate pleurodesis, but comparable with duration in tetracycline pleurodesis in spontaneous pneumothorax. ${ }^{6}$

There was no significant difference in liver function tests and electrolytes before and after doxycycline pleurodesis even after reinstallation, in agreement with other reports. 6,8

The most common adverse effects with doxycycline pleurodesis were dyspnea, chest pain and fever, which were mild and transient as compared with those that occurred with silver nitrate and talc slurry pleurodesis in spontaneous pneumothorax and 
cardiac hydrothorax. 6,10,11 There was no contralateral recurrence of hydrothorax. Davidoff et al., 1993 reported contralateral recurrence in hydrothorax secondary to heart failure. ${ }^{11}$

This prospective study shows that the intrapleural injection of $500 \mathrm{mg}$ doxcycline through a chest tube is an effective treatment for patients with symptomatic hepatic hydrothorax, not responding to medical treatment and repeated thoracocenteses, with minimal adverse effects.

\section{References}

1. Lieberman FL, Hidemura R, Peters RL, Reynolds TB. Pathogenesis and treatment of hydrothorax complicating cirrhosis with ascites. $1966 \mathrm{Feb} ; 64(2): 341-51$.

2. Seeff LC, Seeff, LB. Pulmonary disorders and the liver. In: Gitlin N. The liver and systemic disease. New York, Edinburgh, London, Madrid, Melbourne, San Francisco, Tokyo: Churchill Livingstone, 1997. p. 17-42.

3. Sahn SA. State of the art. The Pleura. Am Rev Respir Dis. 1988 Jul;138(1):184-234.

4. Sudduth CD, Sahn SA. Pleurodesis for nonmalignant pleural effusions. Recommendations. Chest. 1992 Dec;102(6):1855-60.

5. Spencer EB, Cohen DT, Darcy MD. Safety and effi- cacy of transjugular intrahepatic portosystemic shunt creation for the treatment of hepatic hydrothorax. J Vasc Interv Radiol. 2002 Apr;13(4):385-90.

6. Wied U, Halkier E, Hoeier-Madsen K, Plucnar B, Rasmussen E, Sparup J. Tetracycline versus silver nitrate pleurodesis in spontaneous pneumothorax. J Thorac Cardiovasc Surg. 1983 Oct;86(4):591-3.

7. Susla GM, editor. The handbook of critical care drug therapy. $2^{\text {nd }}$ ed. Lippincott Williams \& Wilkins; 1998.

8. Pestal M. Doxycycline in the treatment of respiratory tract infections. Results of a pan-European multi-centre trial. Chemotherapy. 1975;21 Suppl 1:91-108.

9. Deebes, AM, Abdou OM. Talc slurry pleurodesis in hepatic hydrothorax. J Egyptian Society of Cardiothoracic Surgery. 1996 Apr;4(2).

10. Kennedy L, Rusch VW, Strange C, Ginsberg RJ, Sahn SA. Pleurodesis using talc slurry. Chest. 1994 Aug;106(2):342-6

11. Davidoff D, Naparstek $Y$, Eliakim M. The use of pleurodesis for intractable pleural effusion due to congestive heart failure. Postgrad Med J. 1983 May;59(691):330-1.

\title{
Become a Member of IMANA!
}

\author{
For information on joining IMANA \\ or renewing your membership, visit
}

http://www.imana.org/mc/page.do?sitePageld=5701

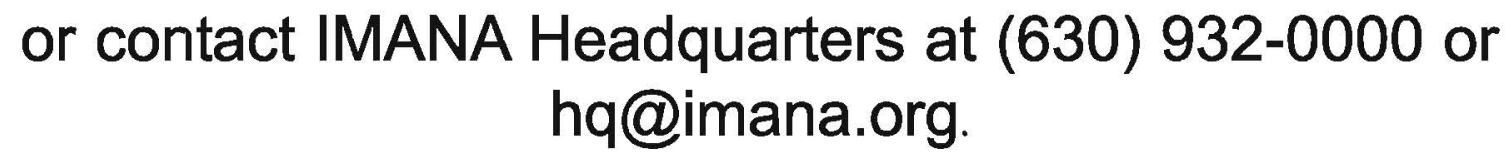

